\title{
3. Four narratives of overcoming early job insecurity in Europe: a capability approach
}

Kjetil Klette Bøhler, Veneta Krasteva, Jacqueline O'Reilly, Janikke Solstad Vedeler, Rumiana Stoilova and Ida Tolgensbakk

\section{INTRODUCTION}

Overcoming early job insecurity is a demanding challenge for young people, even when labour market conditions are favourable. Over the past decades, young Europeans have had to face some very significant obstacles: the economic crisis of the 1980s, the collapse of the communist regimes and, most recently, the financial crisis. These major economic and political upheavals have made youth trajectories into adulthood even more arduous. Through a comparative analysis of nine qualitative life-course interviews from seven European countries (Greece, Norway, Germany, Poland, Bulgaria, the United Kingdom and the Czech Republic), this chapter examines the subjective consequences of these challenges.

Four main narratives emerge from our analysis: (1) the Stumbler, (2) the Stigmatized, (3) the Great Crisis and (4) the Messy Life. The Stumbler narrative encompasses life-course trajectories where unemployment and precarious work situations had few lasting consequences for individuals' prospects for meaningful work. The Stigmatized narrative captures young people who have faced lasting difficulties that they attribute to characteristics they are unable to change, for example ethnicity and disability. The Great Crisis narrative refers to groups of people trying to find work at a time when significant political or economic upheavals hampered these attempts. We focus here on the financial crisis of 2008, looking at how broader macro-structural changes impacted on young people's personal sense of active agency. Lastly, the Messy Life narrative characterizes individuals who question society's ideals about work-life balance and develop 
alternative visions of the life they want to live that contrast with the norms and values of their social peers.

Conceptually, we interpret these four narratives through the lens of the capability approach (Sen, 1992, 1993, 2009) to demonstrate how each narrative expresses different forms of capability - here meaning the extent to which we can live a life that we have 'reason to treasure' (Sen, 2009: 227), despite facing different levels of adversity in diverse societal arrangements. We pay particular attention to the conversion factors that enable or prevent individuals' conversion of their social, economic or political resources so as to enhance their capabilities. This analysis goes beyond quantitative approaches by providing an in-depth understanding of how individual actors perceive these challenges, what they are capable of doing about them, what resources would help them to make successful transitions, and how these insights can inform policymaking at both the European and the local levels.

Much cross-national comparative research on the consequences of youth unemployment and precarious employment has been conducted in recent years, focused either on secondary analysis of large-scale data sets or on policy evaluation (Ayllón and Nollenberger, 2016; Blustein et al., 2013; Fryer, 1997; Kieselbach, 2003; McLaughlin, 2013; O’Reilly et al., 2015, forthcoming; Strandh et al., 2014; Wanberg, 2012). However, there are few cross-national qualitative studies of the subjective effects of unemployment (Tanum and Krogstad, 2014). Existing qualitative approaches have tended to focus on specific cases from individual countries (Gabriel et al., 2010; Shildrick et al., 2012). This lack of systematic qualitative cross-national comparison is due in part to the complexity of conducting such research in different languages and institutional settings. This chapter addresses this gap by examining the extent to which the narratives of young Europeans experiencing job insecurity have commonalities across nation states, while also defining the specificity of these narratives' particular societal contexts. As such, this research is an important, original and innovative contribution to the debates around how young people have managed to overcome early job insecurity in Europe. We discuss our use of the capability approach and briefly summarize our methodology and research design before presenting the evidence from these interviews and our conclusions.

\section{THE CAPABILITY APPROACH AND SEVEN CONVERSION FACTORS}

Amartya Sen's capability approach $(1992,1993,2009)$ draws attention to a person's relative freedom and opportunity to live a life according to his 
or her visions and values in a given context. While this approach has been widely adopted, it has seldom been used to explore youth employment (Bussi, 2016). In using this theoretical framework, we go beyond economic studies and their focus on productivity and human capital accumulation. We consider instead the extent to which young unemployed or those with insecure jobs are able to live their lives according to their personal needs and wants (Otto, 2015).

Sen describes a person's realization of capability in practice as his or her functioning (Sen, 1992: 40). Functionings can vary over time and be influenced by a wide range of what Sen calls conversion factors (1981: 26-30). A conversion factor is a way in which a person can convert a resource to improve his or her capability, and these resources and forms of conversion can vary across groups, in different geographical locations and over time.

Robeyns (2005) distinguishes between personal, social and environmental conversion factors that impact on a person's functionings:

First, personal conversion factors (e.g., metabolism, physical condition, sex, reading skills, intelligence) influence how a person can convert the characteristics of the commodity into a functioning. . .Second, social conversion factors (e.g., public policies, social norms, discriminating practises, gender roles, societal hierarchies, power relations) and, third, environmental conversion factors (e.g., climate, geographical location) play a role in the conversion from characteristics of the good to the individual functioning. (Robeyns, 2005: 99)

Sen (in Hvinden and Halvorsen, 2017: 5) differentiates between five types of conversion factors: (1) personal heterogeneities, that is, the diversity of individual characteristics (e.g., physical and mental capacities, knowledge and skills); (2) distributions within the family, such as the extent to which family relations influence a person's capability (e.g., by providing services, networks, economic capital and the gendered division of labour); (3) differences in relational positioning (e.g., cultures, social norms and conventions that negatively affect one's respect for others, and a sense of dignity, self-respect and 'ability to appear in public without shame'; (4) varieties in social climate (e.g., the quality of public services and community relations); and (5) environmental diversities (e.g., climate, differential exposure and risk of illness).

Despite the significant explanatory power of Sen and Robeyns's understandings of conversion factors, we argue that their sub-categories are both too few and too broad to adequately capture the complex empirical reality that shapes a person's sense of capability in practice. For example, by grouping such various phenomena as 'public policies, social norms, discriminating practises, gender roles, societal hierarchies and power relations' within a broad rubric termed 'social conversion factors' (Robeyns, 
2005: 99), Robeyns does not pick up on specific experiences of these diverse factors. For instance, a specific public policy to promote gender equality may have little traction where discriminatory practices and social norms are not supportive of such policies. The broad dimensions included in Robeyns's social conversion factors are not sufficiently fine-grained.

We therefore propose a more nuanced conceptual framework of seven conversion factors, building on and expanding Sen and Robeyns's arguments. This approach allows us to identify the complex contextual factors affecting youth unemployment and job insecurity transitions amongst young adults. We propose using the following seven conversion factors: (1) institutional, (2) social, (3) familial, (4) economic, (5) cultural, (6) political and (7) personal.

Institutional conversion factors address the impact of institutions (either state-run or non-state) on a person's sense of capability - that is, the ways in which a school, an unemployment agency office or a football club might alter a person's ability to live a life according to his or her visions and values. Social conversion factors address the abiding influence of individual friends, friend groups or social networks on personal capability. Familial conversion factors associate capability with relations within the family. Economic conversion factors address an individual's income and wealth in relation to capability. Cultural conversion factors capture capability's relationships to cultural norms, practices and customs, such as, for example, how discrimination against ethnic groups or expected patterns of behaviour related to gender may enable capability for some people and hinder it for others. Political conversion factors designate how larger changes in the politics or economy of a nation (e.g., the impact of a financial crisis or the change from socialism to capitalism) impact on a person's possibilities for capability. Personal conversion factors address how the active agency of an individual might improve his or her capability, including choices about voluntary versus paid work in relation to an individual's well-being and/or human capital.

Conversion factors can have both positive and negative effects (Halvorsen and Bøhler, 2017: 177; Hvinden and Halvorsen, 2017: 5). In the following analysis we use this approach to examine forms of functioning, while also drawing on Robeyns's (2003) argument that conversion factors all interrelate with gender differences. We also take account of interaction effects between conversion factors causally and over time. These interactions can operate both synchronically (i.e., in how social, familial and institutional conversion factors interplay in time) and diachronically (i.e., how various conversion factors affect causal relationships over time). In addition to the analytical framework provided by the capability approach and our nuanced set of seven conversion factors, we also draw on Tannen's (2008) concept of big-N and small-n narratives to allow us to interpret our data. 


\section{METHODOLOGICAL APPROACH: BIG-N AND SMALL-N NARRATIVES}

A 'big-N' narrative develops 'a storyline or theme that functions as a coherence principle organizing a speaker's discourse' (Tannen, 2008: 227). Each narrative is identified based on the interpretation of what Tannen terms 'small-n' narratives, or 'accounts of specific events and interactions that speakers told' (Tannen, 2008: 209). Small-n narratives are defined as micro-level accounts of specific events experienced by the interviewees. Analysis of statements from these individual narratives builds evidence for the big- $\mathrm{N}$ narratives.

Here we use narratives to identify our respondents' most common accounts of unemployment and job insecurity, looking at how these narratives manifest different functionings for groups of individuals across countries and cultural contexts. We focus on general and shared experiences, while keeping societal specificities in sight. By drawing upon subjective narratives about the extent to which an unemployed individual can live a life according to his or her own needs and wants, we transcend common binary views that differentiate between only productive and nonproductive labour forces. In this way we can understand how participation in the public sphere of economic production and paid employment is shaped by the private sphere of social reproduction specific to that individual (O'Reilly et al., 2017). These various unique stories or narratives about different functionings contribute to narratives that encompass both national context and issues of intersectionality.

\section{RESEARCH DESIGN}

This study analyses nine qualitative life-course interviews with men and women born in three birth cohorts (1950-55, 1970-75 and 1990-95) in seven European countries: Bulgaria, the Czech Republic, Germany, Greece, Norway, Poland and the United Kingdom. We focused on interviewees with a high-school level of education who had been unemployed or in a precarious work situation for more than four months before the age of 25 (for details of the qualitative data collection and method, see Hvinden et al., Chapter 1 this volume).

All interviews were based on a common interview guide initially developed in English in an iterative process between the research teams, while the final versions were translated into the relevant local languages. The interview guide was thematically organized, and each interview lasted between one and two hours. The interviews were conducted between May 
2016 and November 2016; all were tape-recorded and then transcribed into the relevant national language. Summary reports of each interview were translated into English so that the material could be shared and analysed by all the research teams.

All interviewees have been anonymized using pseudonyms. Ethical approval ensuring that vulnerable respondents and the researchers themselves were covered by a duty of care was obtained from the Norwegian Centre for Research Data, as well as local ethical research committees at the universities in the respective countries.

\section{FOUR NARRATIVES: SUBJECTIVE EXPERIENCES OF EARLY JOB INSECURITY}

We identified four narratives in our data: the Stumbler, the Stigmatized, the Great Crisis and the Messy Life. The Stumbler narrative captures life stories where the experience of unemployment or precarious employment had little overall impact on a person's sense of capability. Drawing on a range of conversion factors, these individuals eventually secured work they liked and found to be meaningful. The Stigmatized narrative refers to those experiencing recurring unemployment that they attributed to characteristics they could not change, such as ethnicity and disabilities. The Great Crisis narrative points to macro-structural political conversion factors as exceptional obstacles to overcoming early job insecurity. Finally, the Messy Life narrative characterizes individuals whose visions concerning the lives they wanted to live were alternative to the dominant norms and values of their social peers. The cases selected below illustrate these different narratives and analyse the complex interplay between specific functionings and conversion factors.

\subsection{The Stumbler Narrative}

Born in the 1970s in the eastern part of Norway, Thor finished uppersecondary school in the early 1990s, completing his final exams a little late following his obligatory military service. Gaining admission to a university was hard at that time because high levels of unemployment had resulted in more applicants, which inflated grade requirements. Thor's job applications were equally unsuccessful; he recalled that there were almost no job opportunities throughout 1992. Still, he managed to live independently by paying a relatively cheap rent to a friend and roommate and drawing unemployment benefits as an entitlement resulting from his military service; he also worked on Saturdays as a postman. 
The focal point of his social life was hanging out at the local pub on weekdays, together with other unemployed young men like himself. Thor described the pub as both a space for creating social networks and an arena for intellectual stimulation, while acknowledging the temptations of late-night drinking:

I was at the local pub almost every day; we drank but didn't always get drunk. Whoever had money bought the beer, that was part of the social thing. . That pub became essential in our lives. We even went there on Christmas Eve after we had been with our families; it became 'our place'...We also talked about real stuff at the pub. I remember we discussed Hannah Arendt, Machiavelli, Aristotle and Plato. We had great discussions. It made me really interested in political theory. (Thor)

As a consequence of this intellectual awakening, Thor started dreaming about studying philosophy and political science.

After being unemployed for a year and a half, Thor eventually found a temporary job at the municipal administration. When he asked his boss why he had been chosen out of 223 applicants, the man replied that the reason was his good grade in English and his work experience and work ethic, evidenced by the fact that he had been a Saturday postman since he was 16 years old. Thor said that this job was a turning point in his life because it provided him with a better income and raised his self-esteem. When it came to an end, he was once again unemployed for nearly a year until he found another temporary job in the administration of the federal government; this position ultimately led to permanent work. However, after a few years Thor felt limited as to what he could achieve in this permanent job and decided he needed better qualifications, so he applied to the university and was admitted. After completing a degree in politics in three years, in 2001 he secured a relevant and permanent position that he loves in the welfare administration of the public sector; he has now been there for 15 years.

\section{Identifying conversion factors in Thor's story}

Read in the light of the theoretical framework presented above, Thor's story illustrates a complex interplay of positive and negative conversion factors that influenced Thor's functionings, operating on different levels. First, on the one hand, we see how the military worked as a negative institutional conversion factor by delaying his entry into university studies and, subsequently, the labour market. This conversion factor implicated gender as well, as it was mandatory for young men to do military service at this time. On the other hand, the military also improved Thor's functioning by entitling him to unemployment benefits, thanks to the Norwegian 
National Insurance Act, ${ }^{1}$ meaning that it also worked as a positive institutional conversion factor.

In this case two institutional conversion factors were coupled diachronically - the institution of the military and the institution of the Norwegian welfare apparatus (represented by the folketrygd law). The ways in which Thor managed to survive economically - his low rent, thanks to a friend, and his long-term Saturday job as a postman - are two positive conversion factors. The income from his Saturday job, together with his unemployment benefits, acted as an economic conversion factor that enabled him to meet friends at the pub and live independently of his family in his early 20s. In addition, Thor's close friend/room-mate and the pub community acted as social conversion factors, because they influenced Thor's well-being and sense of autonomy by providing him with a social network and a space for engaging discussions and intellectual growth. Of course, they also exposed Thor to regular alcohol consumption. In this sense, the pub as a social conversion factor influenced Thor's sense of capability positively and negatively at the same time.

However, it was personal conversion factors - that is, the human capital and positive harbinger represented by a good grade in English and ten years of work as a postman - that gave Thor his first job. While this job experience was translated temporally into further personal conversion factors by leading to other jobs afterwards, hence increasing Thor's human capital, he also mobilized impressions from his pub conversations to rethink what he wanted to do. He decided that his current job at the time was not enough for him; moving into higher education enabled him to get a more stimulating and stable job in welfare administration. Earlier conversion factors interacted diachronically and changed Thor's perceptions of the life he wanted to live (i.e., discussing political theory at the pub, along with his Saturday job, enabled him to buy the beers and participate in the pub community). This diachronic perspective underscores the fact that a person's sense of capability cannot be viewed as either static or given but must be viewed as dynamic and changing according to his or her preferences.

\section{Female stumblers and the role of gender}

In contrast to Thor, the female Stumbler narratives added early motherhood as a gendered key point. Many individuals reported that they had to postpone higher education and labour market entry after giving birth at an early age. For example, Helena, born in the early 1990s in the Czech

1 See Lov om folketrygd, dated 28 February 1997, paragraphs 4-16. 
Republic, became pregnant while still in upper-secondary school and felt that this delayed her career path. She had to work in low-skilled jobs (as a cleaner and in a warehouse) throughout the week and study at weekends to sustain herself in her early 20s. She was, in turn, very dependent on her family to help her take care of her son and assist her financially when she could not make ends meet:

If my parents had not helped me, I would be doing really bad. . .They support me a lot. They take care of my son on weekends when I am attending school. . . They support us financially. . .My sisters support me; they have kids, so they give me their clothes and stuff. (Helena)

While Helena described this time in her life as hard because of periods of unemployment followed by job insecurity, she ultimately returned to her secondary education, with a focus on nursing and social services.

Framing Helena's story using the theoretical framework, we see that her family served as a familial conversion factor that enhanced her capability as a young mother in that both her parents and her sisters helped her to realize the life she wanted to live with her new-born son. This familial conversion factor manifested itself by providing financial support (parents) and baby clothes (sisters), as well as providing services in the sense of taking care of Helena's son during the weekend (parents).

Most of the female Stumbler narratives referred to the importance of family (partner or parents) as 'significant others' (Ayllón et al., Chapter 9 this volume) in overcoming problems related to unemployment, which underscores a gendered difference with regard to how individuals cope with unemployment.

Thor and Helena's stories are classified as Stumbler narratives because both these individuals were able to recover from their struggles with unemployment and develop careers. This was thanks to multiple and converging conversion factors that operated both synchronically (in different domains, such as the interplay between social and economic conversion factors) and diachronically (such as the sequence of temporary jobs that led both Thor and Helena to a permanent position).

\subsection{The Stigmatized Narrative}

In contrast, the Stigmatized narrative refers to people who experience consistent difficulties that they attribute to characteristics they cannot change, such as disability or ethnicity. The life-course interviews with Astrid from Norway and Adléta and Osvald from the Czech Republic illustrate these trajectories. 


\section{Disability discrimination}

Astrid was born with a physical disability in southeast Norway in the early 1990s and always had a strong ambition to work in the field of health management. After finishing upper-secondary education with a specialization in that field, she found herself unable to secure work. She disclosed her disability on her applications because Norwegian employers are legally forbidden from discriminating against people with disabilities. In retrospect, though, she wondered whether this was why she was never called to a job interview. After applying for hundreds of jobs over a period of seven years and participating in multiple internships through state-organized active labour market policies (ALMP), she lost all faith in such measures:

I have been in and out of work training measures for seven years. It's two months here, three months there and five months there. It would have been fine if it got me something permanent afterwards. But I am often told early on that I will never get a permanent position. They call it 'work training'. But I do not want that. I want to be in a job environment where I can participate and be useful. I don't want to be free labour; I want to be useful. (Astrid)

As evidenced by Astrid's repetition of the word 'useful', her main goal was to find work that she liked and where her knowledge was valued. At the time of the interview, Astrid had given up: all she wanted now was a disability pension, 'so that I at least have a stable income'. She felt that a disability pension would relieve her of the pointless 'work training', as well as enable her to find part-time jobs that would fit in with her disabilityrelated health issues.

Astrid's story illustrates how cultural and institutional conversion factors worked in tandem and negatively contributed to her sense of capability (Halvorsen and Bøhler, 2017; Hvinden and Halvorsen, 2017). She perceived cultural conversion factors as discrimination because her disability damaged her ability to find permanent work. The state-sponsored ALMP programme that provided Astrid with an internship operated as an institutional conversion factor that was supposed to supply her with relevant experience to find more stable employment. However, it had no positive long-term outcome. Instead, Astrid went from one internship to another. What could have been positive conversion factors instead led to a string of new trainee programmes, ultimately culminating in her losing faith in her dream of working in health management. The feedback loop between the negative cultural conversion factors (disability discrimination) and the negative institutional conversion factors (internships from the ALMP programmes) made Astrid reconsider her sense of capability. At the time of the interview, she said that she was at the point of trying to formulate new ideas about the life she wanted to live and about how she 
could qualify for a permanent disability benefit to provide her with some financial security.

\section{Roma discrimination}

Adléta was born in the early 1990s in the Czech Republic; she finished primary school at the age of 15 and tried to find a job. After a year, she became pregnant and stayed home for three years with her child until she was 19. She was living with her grandmother and received only a minimal amount of social assistance. Except for temporary, low-paid jobs, her job search was ultimately unsuccessful. Although her extended family helped her to survive, most of them were unemployed and had little interest in further education. Poverty thus became a vicious circle: with no way to pay for childcare or public transport, Adléta had few options remaining to her. She decided that discrimination and her lack of education were the main obstacles to her success:

They don't give me work just because I am Roma. Being Roma is much more difficult than being just Czech. But it is also difficult for me to find work because I have only lower-secondary education; but being Roma also makes it difficult to enter higher education. Everything is more difficult if you are Roma. (Adléta)

Adléta said she would have accepted just about any job to get the money to raise her child because her access to welfare benefits as a Roma in the Czech Republic was very limited. She was depressed and lacked confidence, expressing great worry about the future due to the difficult situation she was in.

Interpreting Adléta's story, we can see how supportive familial conversion factors were keeping Adléta and her child afloat, but little more. As part of a poor Roma family, Adléta could not expect her family to motivate her: her family had no experience with higher education or business networks to give her work experience. Economic conversion factors also put Adléta in a difficult position in that her poverty hindered her movement and choice of employment. In addition, we can see how two institutional conversion factors, represented by her lack of education and her lack of access to welfare benefits, interplayed synchronically with broader cultural conversion factors related to discrimination against Roma people in general. This synchronic interplay restricted Adléta's possibilities for living a meaningful life that was in line with her own needs and desires. Gender in the form of early motherhood added to her burdens.

A similar experience of a stigmatized narrative is found in the case of Osvald, a Czech Roma born in the 1970s. He left school at age 16 and worked in construction as a low-qualified bricklayer. In the interview he 
frequently compared the earlier communist era to his current situation: the past was much better. Before the 1989 revolution he had been a carpenter. In the early 1990s he found it more difficult to find work and it was only with the help of his father that he found a short-term job in a foundry. Welfare reforms introduced after the 1989 revolution meant that Osvald was able to contact several unemployment offices, but he felt that he never got the services and support that he was entitled to; they always perceived him as 'just a lazy Gypsy with no education who doesn't want to work' (Osvald). It was his ethnic identity that he felt disadvantaged him most during this period. Feeling excluded from society with no job security made him deeply depressed, stressed and frustrated, to the point that he began self-harming.

I could not eat, I was in a bad mental state, I was so frustrated and I gave up. . .I begged for work every day. I had to get up and do the same thing every day; every morning I went to the unemployment office and I was told 'no' again and again. I even started to cut myself [shows his arm with thin scars]. I was depressed. (Osvald)

Self-harming worsened both his physical and his mental health, in addition to feeling inadequate at supporting his wife and three children. At the same time, his family was also a source of strength and motivation:

You know what gives me strength? The fact that I have a family! I have kids and a wife, I have to care for them, I have to provide. I cannot lie on the ground and die. (Osvald)

Reading Osvald's story through our theoretical framework, we can see how multiple political, institutional and cultural conversion factors interacted synchronically and negatively to impact on his sense of capability. A general political conversion factor is present in Osvald's description of the regime change from socialism to capitalist democracy following the Velvet Revolution of 1989 and his subsequent loss of work. Institutional conversion factors included Osvald's experiences with the new unemployment offices over the past two decades, which damaged his self-esteem by failing to improve his condition. This condition was linked to a cultural conversion factor represented by increased discrimination against the Roma people after the revolution. The ways in which these three conversion factors interplayed synchronically and diachronically left Osvald in a precarious state, as was apparent from his description of self-harming and deep depression. While the familial conversion factor represented by his wife and three children potentially added to his burden, Osvald noted that his family also had a positive influence on his well-being, providing 
him with the strength and motivation to continue the fight. This dual conversion factor, which both positively and negatively impacted on Osvald's sense of capability, was tied to gender roles and Osvald's view of himself as the male breadwinner.

The stories of Astrid, Adléta and Osvald illustrate how the challenges to find stable employment were inter-related with stigmatization and also how their sense of capability deteriorated. These stories also illustrate the complex synchronic and diachronic interplay between cultural and institutional conversion factors that fuel discrimination on multiple levels across societies.

\subsection{The Great Crisis Narrative}

The 'Great Crisis' narrative represents people whose negative capabilities stem from the consequences of the Great Recession following the financial crisis in 2008. Here we draw on two cases - Theodora from Greece and Nikolai from Bulgaria.

Theodora was born in the south of Greece in the early 1990s and finished high school as the effects of the 2008 financial crisis were completely transforming Greek society. She spent six months applying for jobs until she eventually found some temporary, poorly paid, low-quality work handing out leaflets and providing childcare through contacts with friends and acquaintances. None of these jobs provided any security, so she did not know from one day to the next if she would be employed again. Whilst unemployed she registered at the public unemployment agency, even though she was not receiving unemployment benefits. Her lack of economic independence meant she had to remain living with her parents, although she would have preferred to move in with her boyfriend and start a family. All of these options were on hold. The constant job insecurity affected her sense of identity and mental health as a series of disappointments lowered her self-esteem:

[The lack of work] is a piece of your everyday life. A job gives you an identity, a sense of self. . .Job insecurity or being uncertain about your work situation and being constantly disappointed after having your applications rejected, that all defines you as a person. To a certain degree you lose faith in yourself, you lose your self-confidence, it changes you day by day. . .I felt like life didn't give me back any joy. (Theodora)

The only reliable support she received during these hard times was moral encouragement and economic assistance from her family. She was very sceptical about the support provided by the state via various employment programmes: 
Work training programmes that last for five months do not provide any solution; afterwards people are unemployed again. The thing they need to do is to create real job positions and maintain them. If they don't create a climate of growth for companies there is no chance to solve [the problem of] unemployment. Employment programmes don't solve the problem, they are certainly a temporary relief, but they are something temporary. . .I would prefer for people to be able to find a job on their own, without the help of any programme, that would be ideal. (Theodora)

Because of the lack of work prospects, Theodora decided to study information technology and English on her own, and to volunteer in a childcare programme organized by a church:

While I was applying for jobs and nothing was coming out of this, a neighbour told me about this project run by the parish. It wouldn't give me any material profit or remuneration; it was only voluntary work for others, with a specific focus on voluntary work for families with children. And since I was very interested in this, and particularly in children, I saw it as an opportunity to acquire some experience of working with children, even on a voluntary basis. First, I gained some experience that I needed, because it was before I started working as a babysitter, and secondly it helped me psychologically, I felt creative again. (Theodora)

Theodora hoped that her studies would pay off in the future and she had faith in better times to come.

Multiple conversion factors interplayed to hamper Theodora's sense of capability. First and foremost, the political conversion factor represented by the economic crisis put impossible conditions upon the life Theodora wanted to live, as unemployment rates had risen to around 50 per cent amongst young adults in her country, which made work very hard to find. In addition, institutional conversion factors represented by mandatory visits to the unemployment office added to her burden without providing any actual support. Throughout this difficult situation, Theodora's friends and acquaintances came to represent a positive social conversion factor in that they enabled her to find work against all odds. The support from her family also represented a positive familial conversion factor. Both the social and the familial conversion factors interacted with a positive personal factor represented by her volunteer work and ongoing studies to strengthen her sense of well-being and enhance the human capital she hoped would lead her to work in the future.

Nikolai, who was born in the 1990s in Bulgaria, provides a contrasting example of a Great Crisis narrative. Against all the odds, he got his first job in the printing sector during the first three years of the economic crisis, between 2007 and 2010, right before he completed his upper-secondary education. However, in 2010, during the peak of the crisis in Bulgaria, 
he left his job as a result of decreased market demand and a reduction in pay. After applying for other work in the same field for six months with no success, he started work as a plastic machine operator, despite having no skills in this area and finding the pay to be low here too. Nikolai was the breadwinner of the family, supporting his wife, son and new-born daughter, which continuously drove him to seek better pay in the throes of the crisis. Thanks to his new skills and his social network at work, Nikolai was soon able to find new work with better pay in the same field. A couple of months later, however, the company went bankrupt, and he was unemployed for around four months. Nikolai recalls it as a tough time:

I was depressed and unhappy then. I was the head of the family but could not prove myself as such, I couldn't provide for my family. My self-confidence was deeply affected. . Then I drank. I drank a lot. But that only helped me for a while. I stopped eating and lost a lot of weight, I remember - my weight was only $48 \mathrm{~kg}$ at the worst, compared to now, when my weight is $95 \mathrm{~kg}$. (Nikolai)

The effect on Nikolai undermined his masculine identity as breadwinner for his family. This feeling of failing as a man affected him both mentally (his depression) and physically (his weight loss). Eventually, a neighbour helped Nikolai connect with a foreign company, where he has worked for the last four years for decent pay, enabling him to take care of his family.

Various conversion factors are at play in Nikolai's narrative. First, a personal conversion factor - his role as male breadwinner - prevented him from seeking institutional support because of issues of pride. Understood in terms of the capability approach, this personal conversion factor (breadwinner identity) blocked Nikolai from accessing other possible forms of institutional conversion factors such as support from the state through various programmes. Nonetheless, other personal conversion factors, represented by a good knowledge of English and a willingness to work hard, eventually became economic conversion factors by increasing Nikolai's income and allowing him to fulfil his breadwinner ideals. When Nikolai's life course was at its worst he relied heavily on support from his relatives and friends (positive social conversion factors) and his wife (familial conversion factor).

Taken together, these examples of Great Crisis narratives demonstrate how one powerful political conversion factor can severely hamper an individual's sense of active agency, and how this factor then interacts with institutional, social, familial, economic and personal conversion factors in complex ways as well. While these synchronic and diachronic interactions usually have a negative impact on one's sense of capability, the data also demonstrate that people are sometimes able to mobilize active agency, 
against all odds, thanks to positive feedback loops between specific conversion factors (e.g., between social, familial and personal conversion factors, as in the case of Theodora).

\subsection{The Messy Life Narrative}

Young people who follow trajectories that result in 'messy lives' have often chosen pathways outside of mainstream life.

Moritz, born in Germany in the 1950s, spent his adolescence, in the early 1970s, hitchhiking across Europe. He became part of a punk culture nurturing an alternative ideology about life values. He felt disorientated and separated from a bourgeois way of living. Rather than getting a job and a steady income, Moritz wanted to enjoy life and not have the responsibilities associated with a full-time job:

The times back then were of great importance to me. It was just going out a lot, being out and about at night. And also the first experiences with drugs. . This was more appealing to me and this was more my world than going to work somewhere. (Moritz)

He suffered periods of illness and of living on the streets. He nevertheless chose to live this way for many years while he was in his 20 s because he wanted to 'be free of societal pressure and live in the moment'. Following on from a series of chaotic legal and illegal jobs, and consuming various drugs on a regular basis, Moritz responded in his late 20s to his father reaching out to him and persuading him to find a more stable job. His father was able to convince him to finish his training as a construction worker, which led to steady employment for a short time. However, Moritz found it impossible to keep down a regular job:

I was unemployed for quite some time. And I bummed around a lot. I did not feel like doing anything at all. I also had a lot of conflict with my father for this reason because he had a very strict ethos concerning work and a disciplined life. (Moritz)

His father reached out to him again and this last intervention resulted in Moritz finishing his training in social work:

. . actually I had not grown up on the whole. But at least I recognized that I couldn't go on with my life like that. Being unemployed, being homeless, on the go and always in danger of heading for the gutter. (Moritz)

Moritz currently works as a social worker in a homeless shelter, is married and has one child. Looking back, he sees the reason for the period of job 
insecurity and unemployment in his own attitude towards life, which he describes as characterized by denial of responsibility, lack of motivation and disorientation.

Czesław, born in Poland at the beginning of the 1950s, also had a 'messy life' as a result of wanting to be carefree and to have fun: 'At the time, the idea was to earn money and then go have fun without a care.'

Czesław spent most of his professional life working in the informal sector or in illegal activities. He made money from drug dealing and has himself been an addict. He described a sense of freedom, even pride especially because he could earn a higher-than-average income through these activities - as one of the positive aspects of living on the edge of the law. He also made good money working (often informally) in construction and on the railroads. Under communism, when such luxuries were unimaginable to most others, he owned a motorcycle and a car. However, while it was the illegal and dangerous work that enabled him to acquire these luxuries, it was also what got him in trouble: Czesław caused an accident on one of the building sites that ended up with him being imprisoned. He has had periods of relative wealth and had a family, but has also experienced periods of alcoholism, homelessness and loneliness. He claims his sense of pride prevented him from asking for help. At the time we interviewed him, he was waiting for social housing. He has limited entitlement to claim social benefits and has no health insurance because he has rarely earned income within the formal economy. (Czesław's experiences are discussed in more detail in the chapter by Ayllón et al., Chapter 9 this volume, looking at young people's use of drugs.)

Moritz's and Czesław's lives share some similarities, although the outcomes are very different. Both felt a strong need in youth for a different and independent lifestyle. They both made choices that were incompatible with earning a stable income and having a straightforward career trajectory. Regarding the conversion factors involved in these two men's lives, the institutionalized welfare state had little success in interfering in their 'messy life' trajectories. Both men have had long periods of time living on the outskirts of society. Moritz found a positive cultural conversion factor in punk culture, but this was not enough to secure a future. In the case of Czesław, his inner strength and sense of pride is something he himself cites as the factor that has kept him going. In other words, it is an inner, personal conversion factor that enables him to cope with life's ups and downs. In the case of Moritz, however, there is an external conversion factor entering his life, helping him back on his feet - his father. Although he had cut off all contact with his parents, Moritz later reunited with them. Moritz's father, himself an unemployed refugee living on social benefits, managed to convince him to pursue higher education and thus get a 
position in a homeless shelter. This positive familial conversion factor gave Moritz the boost he needed. At a point of his life when he ran a real risk of becoming a delinquent, Moritz found an occupation that suited him and re-entered education and employment.

The Messy Life narratives illustrate the complexities of unemployment and the importance of taking a holistic approach to understanding the various trajectories that may lead to individual unemployment. Although these specific cases seem to point to an element of personal choice, many of the stories we have categorized as messy derive their messiness from factors such as broken homes, abuse or ill health. Reading the stories through the lens of the theoretical framework presented at the beginning of this chapter, personal and familial conversion factors are the most important. The complexities of the unemployment stories in this category, and the reluctance of people with this kind of narrative to seek institutional help, may make it unlikely that they are reached by or are able to receive adequate help from state institutions. However, in other Messy Lives, the security net provided by a strong welfare state is what - at least over time - may turn a Messy Life around.

\section{CONCLUSION}

The aim of this chapter has been to examine the subjective consequences of unemployment and early job insecurity amongst young adults in Europe through interpretive analysis of qualitative life-course interviews from seven countries. We used the capability approach as the theoretical perspective for our analysis and expanded on Robeyns's and Sen's earlier work by proposing a more nuanced conceptual framework of seven conversion factors as lenses for our analysis. We termed these: institutional, social, economic, familial, cultural, political and personal conversion factors. Reading the data through these lenses, four overarching narratives of unemployment emerged across the seven countries we studied: the Stumbler narrative, the Stigmatized narrative, the Great Crisis narrative and the Messy Life narrative.

In brief, the Stumbler narrative captured life stories where the experience of unemployment and precarious employment had little impact on a person's sense of capability. Drawing on a range of multiple conversion factors, these individuals eventually encountered work they liked and found meaningful. The Stigmatized narrative tells of recurring unemployment with a weak connection to the labour market; these individuals remained on long-term unemployment or disability benefits, or in precarious, intermittent fixed-term employment. Obstacles to 
converting any resources they had into a positive sense of capability were limited by a range of intersectional characteristics related to disability, gender and/or ethnicity. The Great Crisis narratives also led to negative capabilities related to long-term unemployment. What distinguished these stories from those of the Stigmatized narrative was the attribution of cause. Macro-structural political conversion factors, such as changes in the political economy, for example following the financial crisis in 2008 , created exceptional obstacles to these people overcoming early job insecurity. Finally, the Messy Life narrative was characterized by people with alternative visions concerning the life they wanted to live - visions that contrasted with the dominant norms and values amongst their social peers. These alternative visions often led to unorthodox, 'messy' life trajectories that, for example, questioned the value of ordinary work trajectories.

While these four narratives enable us to identify different scenarios related to the causes and consequences of early job insecurity, the approach has some limits. There is some overlap between stories that could be allocated to different narratives, for example Moritz's Messy Life narrative could also be read as a Stumbler narrative, in the sense that he was able to recover from his troubles eventually, thanks to the intervention of his father; however, this transition took much longer than for Thor and Helena, so the scarring effects were more profound.

We proposed seven conversion factors that could act as stepping stones for a conceptual framework that is both more nuanced and better equipped to deal with the empirical complexities that influence a person's sense of capability. In addition, despite its shortcomings, the capability approach does not view people solely as instruments for the production of economic growth; instead, it usefully considers the ways in which new types of work correlate with subjective desires and perceptions of wellbeing. In this sense a capability approach can illuminate and redirect our focus towards capability-friendly jobs (Otto, 2015).

\section{REFERENCES}

Ayllón S and Nollenberger N (2016) Are recessions good for human capital accumulation? NEGOTIATE Working Paper no. 5.1. https://negotiate-research.eu/ files/2015/04/NEGOTIATE-working-paper-no-D5.1.pdf (accessed 17 February 2018).

Blustein DL, Kozan S and Connors-Kellgren A (2013) Unemployment and underemployment: A narrative analysis about loss. Journal of Vocational Behavior 82(3): 256-65.

Bussi M (2016) Straightjacket and stepping stones. Exploring institutional ability 
to develop employability of young people. PhD thesis, University of Geneva, Switzerland.

Fryer D (1997) International perspectives on youth unemployment and mental health: Some central issues. Journal of Adolescence 20(3): 333-42.

Gabriel Y, Gray DE and Goregaokar H (2010) Temporary derailment or the end of the line? Managers coping with unemployment at 50. Organization Studies 31(12): 1687-712.

Halvorsen R and Bøhler KK (2017) Transitions to active citizenship for young persons with disabilities - virtuous and vicious cycles of functionings. In: Halvorsen R, Hvinden B, Beadle-Brown J, Biggeri M, Tøssebro J and Waldschmidt A (eds) Understanding the Lived Experiences of Persons with Disabilities in Nine Countries: Active Citizenship and Disability in Europe, vol. 2. Abingdon, UK: Routledge, pp. $175-91$.

Hvinden B and Halvorsen R (2017) Mediating agency and structure: What role for conversion factors? Critical Sociology. Epub ahead of print 9 January 2017. DOI: $10.1177 / 0896920516684541$.

Kieselbach T (2003) Long-term unemployment among young people: The risk of social exclusion. American Journal of Community Psychology 32(1/2): 69-76.

McLaughlin E (2013) Understanding Unemployment: New Perspectives on Active Labour Market Policies. Hoboken, NJ: Taylor and Francis.

O'Reilly J, Eichhorst W, Gábos A, Hadjivassiliou K, Lain D, Leschke J, McGuinness S, Kureková LM, Nazio T, Ortlieb R, Russell H and Villa P (2015) Five characteristics of youth unemployment in Europe: Flexibility, education, migration, family legacies, and EU policy. SAGE Open 5(1):1-19. DOI:10.1177/2 158244015574962.

O'Reilly J, Leschke J, Ortlieb R, Seeleib-Kaiser M and Villa P (eds) (forthcoming) Youth Labor in Transition: Inequalities, Mobility, and Policies in Europe. New York: Oxford University Press.

O'Reilly J, Smith M and Villa P (2017) The social reproduction of youth labour market inequalities: The effects of gender, households and ethnicity. In: Grimshaw D, Fagan C, Hebson G and Tavora I (eds) Making Work More Equal: A New Labour Market Segmentation Approach. Manchester, UK: Manchester University Press, pp. 249-67.

Otto H-U (ed.) (2015) Facing Trajectories from School to Work: Towards a Capability-Friendly Youth Policy in Europe. Dordrecht: Springer.

Robeyns I (2003) Sen's capability approach and gender inequality: Selecting relevant capabilities. Feminist Economics 9(2/3): 61-92.

Robeyns I (2005) The capability approach: A theoretical survey. Journal of Human Development 6(1): 93-117.

Sen A (1981) Poverty and Famines: An Essay on Entitlement and Deprivation. Oxford, UK: Oxford University Press.

Sen A (1992) Inequalities Reexamined. Oxford, UK: Clarendon Press.

Sen A (1993) Capability and well-being. In: Nussbaum MC and Sen A (eds) The Quality of Life. Oxford, UK: Clarendon Press, pp. 30-53.

Sen A (2009) The Idea of Justice. London, UK: Allen Lane.

Shildrick T, MacDonald R, Webster C and Garthwaite K (2012) Poverty and Insecurity: Life in Low-pay, No-pay Britain. Bristol: Policy Press.

Strandh M, Winefield A, Nilsson K and Hammarström A (2014) Unemployment and mental health scarring during the life course. European Journal of Public Health 24(3): 440-45. 
Tannen D (2008) 'We've never been close, we're very different'. Three narrative types in sister discourse. Narrative Inquiry 18(2): 206-29.

Tanum S and Krogstad A (2014) Fortellinger om livet uten arbeid [Stories about life without work]. Sosiologisk tidsskrift 22(3): 249-75.

Wanberg CR (2012) The individual experience of unemployment. Annual Review of Psychology 63: 369-96. 